\title{
Exploring the challenges experienced by people with disabilities in the employment sector in Australia: Advocating for inclusive practice- a review of literature
}

\author{
Amos Ruhindwa \\ Griffith University \\ Christine Randall \\ Griffith University \\ Jennifer Cartmel \\ Griffith University
}

\begin{abstract}
People with disabilities are generally not considered as able participants in the workforce (paid or volunteer work) and therefore, they often experience exclusion from participating in mainstream employment opportunities. People with disabilities experience various barriers to employment, such as discrimination in the workplace, stigma, prejudice and stereotypes. However, some people with disabilities participate in the workforce and make valuable contributions towards economic development, social capital and wider society. This literature review summarises published research findings about the challenges that people with disabilities experience in pursuing employment opportunities, including volunteering and paid positions; and in undertaking these roles. Furthermore, it explores possible interventions to improve employment outcomes that are effective from the perspectives of people with disabilities. Findings indicate that effective practice takes an inclusive approach and allows clients to take ownership of solutions in relation to addressing the challenges they experience in the employment sector. For this reason, two different community development projects, which particularly focused on employment challenges for people with disabilities, as well as outlining strategies and solutions that promote client ownership were reviewed. Additionally, employment support techniques and strategies, as well as human rights' principles on work and employment for people with disabilities will be debated. Finally, implications for research and practice for the rehabilitation counselling profession and the disability employment services sector are discussed.
\end{abstract}

Keywords: disability, employment barriers, challenges, vocational rehabilitation, community development, labour market, social inclusion, human rights, strategies \& interventions

People with disabilities are under-represented in Australia's workforce and the unemployment rate has been increasing over the past years (Australian Bureau of Statistics [ABS], 2009). Literature indicates that the employment situation for people with disabilities in Australia is worsening and the employment participation rate has dropped from $54 \%$ to $53 \%$ since 2009 (Taleporos, 2014). ABS (2009) census' results indicated that half of the 2.2

Corresponding author: Amos Ruhindwa (amos.ruhindwa@griffithuni.edu.au) 
million working-age disabled people were employed, as compared to almost $80 \%$ of workingage non-disabled people.

Research shows that the employment participation rate for people with disabilities is far less than for other people; and the unemployment rate for this cohort is estimated at 1.5 times higher than for people with no disabilities (ABS, 2003; Commonwealth Department of Social Services, 2011).

People with disabilities are often able and willing to work to become financially independent and to contribute towards community development and wider society (Bruce, 2006; Commonwealth Department of Social Services, 2011; Waterhouse, Kimberley, Jonas, \& Glover, 2010). Despite their readiness to work, people with disabilities often find it difficult to secure sustainable employment (Bruce, 2006; Waterhouse et al. 2010). Participation in employment for people with disabilities is central to achieving social inclusion, as well as contributing to physical and mental health, personal well-being and self-worth (Commonwealth Department of Social Services, 2011). Literature has left no doubt that work encompasses economic, social and psychological benefits (The Royal Australasian College of Physicians [RACP], 2011; Winefield et al., 2002). Work plays a major role in individual lives and has a positive influence on health, well-being, social inclusion and identity (Geisen, 2011; Winefield et al., 2002). In contrast, prolonged work absence, work disability and unemployment have negative health impacts, and as such can negatively affect an individual's health and wellbeing (RACP, 2011).

Increasing employment participation for people with disabilities is part of the Australian government strategy to address labour shortages, as well as reducing economic pressures associated with welfare dependence (Buckup, 2009; Department of Education, Employment and Workplace Relations [DEEWR], 2011). Furthermore, improving employment outcomes for people with disabilities will help in enhancing their quality of life and independence, and at the same time be cost-effective in relation to reducing welfarism (Yeend, 2012). The National Disability Strategy [NDS] indicates that many people with disabilities are frustrated about relying on welfare benefits, such as the Disability Support Pension [DSP], despite having the ability and readiness to work (Commonwealth Department of Social Services, 2011; National People with Disabilities Carers Council [NPDCC], 2009).

\section{Aims of the study}

This literature review is aimed at examining the research questions "What are the challenges experienced by people with disabilities in the employment sector (paid and volunteering work) in Australia?" and "What interventions are effective from the perspectives of people with disabilities?" Hence, this paper will summarise research findings about the main challenges and barriers to meaningful employment for this cohort, addressing current gaps in knowledge, as well as identifying key strategies to improve employment participation for people with disabilities in Australia. The findings will also help inform future research in this area of work.

\section{Method}

\section{Search Methods}

This literature review is intended to provide a brief overview for human service, health and rehabilitation counselling professionals on issues and strategies for individuals with a disability trying to enter the Australian workforce. It does not purport to be a detailed systematic review, but rather an introductory overview of the literature in this field of practice. 
As a result, a broad range of search methods were used that did not limit material to peerreviewed articles, but instead placed value on a diverse range of sources including websites, books and research reports.

In line with the aims of the study, the literature review has a two-fold focus. The first is to understand the barriers to employment faced by people with disabilities in Australia. The second is to explore interventions and strategies that were successful. To address the first part of the research question, a broad range of literature and industry sources that shed light on barriers to employment was reviewed. To address the second part of the research question, articles were selected for review if they contained a well-described intervention, procedure, technique or strategy aimed at improving employment outcomes for the target population. After screening of the abstracts and full-texts, data was extracted from each selected article. Search terms were selected to represent the population of interest (i.e., disability, intellectual, impairment, injury, mental illness, health condition) and the outcome (i.e., work, employment, volunteering, return to work, vocational rehabilitation).

Literature was sourced from Google scholar and computer databases, such as Proquest, SAGE Journals Online, government and legislative publications focused on disability employment; restricting selection to current online key journals and articles published within the last 10 years, and which are relevant to the disability employment sector in Australia. A number of academic databases were searched electronically, including Informit (Humanities and Social Science Collection and the Health Collection), Proquest (Academic Research Library, Health and Medical Complete, Psychology Journals, and Social Science Journals), PsychINFO, Australian Government and Politics database, SAGE Journals Online and Australian Journals Online. The researchers also searched for specific issues and fields of practice, such as disability employment, volunteering, vocational rehabilitation and social inclusion. A manual search, including dissertations and books from the Griffith University library identified other important studies that were not electronically published.

\section{Results}

\section{Barriers to employment}

Literature reveals that people with disabilities often experience exclusion from participating in mainstream employment due to environmental, attitudinal, social and organisational barriers, and not issues relating to the effects of their impairments (Craddock \& McCormack, 2002; Moore \& Fishlock, 2006). Barriers to employment for people with disabilities are linked to stigma, prejudice, stereotypes and discrimination (Moore \& Fishlock, 2006). Furthermore, physically disabled job seekers often experience employment challenges, which are related to natural, rural and built environments and systems' structures (Kulkhanchit, 2002). Mobility issues and inability to effectively carry out activities of daily living are physical barriers that can restrict people with disabilities from fully participating in employment activities (Boyce, Malakar, Millman \& Bhattarai, 1999). Additionally, challenges related to low levels of education and limited psychosocial skills makes it difficult for people with disabilities to compete in the open labour market (Thomas \& Hlahla, 2002). If no improvements are made, lack of opportunity in the education system might have practical implications for future employment prospects for people with disabilities in Australia (Human Rights and Equal Opportunity Commission [HREOC], 2005).

The National Disability Strategy [NDS] is an Australian government initiative that was implemented to address the challenges and improve the lives of people with disabilities and their families (NPDCC, 2009). In its implementation phase, the NDS found that negative 
attitudes and misconceptions from employers who believed that disabled workers could slow the production of their businesses were some of the main barriers to employing this client group (NPDCC, 2009). The scheme identified that employers are concerned about potential risks associated with employing a disabled person, recruitment and maintenance costs, as well as lack of knowledge and access to government and relevant support to assist employers (Domzal, Houtenville \& Sharma, 2008; NPDCC, 2009). This makes it hard for job seekers with disabilities to secure sustainable employment in the open labour market (NPDCC, 2009). Small organisations often express concerns related to lack of knowledge and appropriate support about employing people with disabilities; and as such they tend to be unwilling to employ a person who in their frame of reference exhibits disabling conditions (Domzal et al., 2008).

Most employers are also reluctant to hire a person with a disability due to lack of confidence in the knowledge, understanding and competency to fulfil associated tasks (Waterhouse, et al. 2010. Lack of trust creates anxiety and disengagement for potential employers and interferes with their interest or capacity to build knowledge about the real benefits and disadvantages associated with employing workers with disabilities (Australian Industry Group, 2005; Lewis \& Priday, 2008). Indeed, the Australian Employers Network on Disability [AEND] (2008) emphasised the importance of employers having 'disability confidence'.

Volkoff, Clarke and Walstab (2008) point out that some potential employers are interested in developing effective partnerships, networks and industry relationships with one another for assistance in building their capacity to support the productive employment of workers with disabilities, but express concern that there is a lack of connectivity amongst relevant disability employment organisations. The work of the Australian Employers Network [AEN] on disability employment is critical in actively informing and supporting its members, as well as facilitating the achievement of strong networks and high levels of connectivity amongst relevant employers (Volkoff et al., 2008).

Literature shows that lack of disclosure of a disability is one of the main concerns for employers (CRS Australia, 2012; Waterhouse, et al., 2010; Lewis \& Priday, 2008). Researchers assert that some employers can be frustrated with non-disclosure because they feel that it might create unknown risks, which could be difficult to manage, and if there is disclosure they are at least aware of potential problems and can attempt to manage these challenges (CRS Australia, 2012; Waterhouse, et al., 2010; Lewis \& Priday, 2008). On the other hand, job seekers may be reluctant to disclose their disability because of concerns that they may have a harder time finding work and that everyone in the workplace will know about their disability, rather than only concerned people (CRS Australia, 2012).

In contrast, research indicates that even with no previous experience in this area of recruitment, many employers are open and keen to employ people with disabilities (Domzal et al., 2008). However, despite this openness, they have concerns about a range of issues and lack confidence in their knowledge and capacity to address the different challenges related to employing disabled workers (Waterhouse et al., 2010). It is argued here that disability employment service providers, such as rehabilitation consultants should become 'trusted brokers' in facilitating the employment of their clients to assist employers with recruitment, information on government incentives, managing people with disabilities, workplace adjustments and related support (CRS Australia, 2012; Morgan \& Alexander, 2005).

Despite the concerns of employers excluding people with disabilities from accessing mainstream employment opportunities, research has shown that disabled apprentices and 
workers have been found to be safer on the job; and work attitudes, punctuality and attendance records were ranked as equivalent, and in some cases, better than non-disabled employees (Graffam, Shinkfield, Smith \& Polzin, 2002; Lewis \& Priday, 2008). Consequently, it seems that employers with previous experience in hiring job seekers with disabilities develop a strong commitment and good working relationships with this client group and are interested in employing them in the future (Morgan \& Alexander, 2005; Keating, Beaton \& Foster, 2007; Smith, Webber, Graffam \& Wilson, 2003). Furthermore Graffam, et al. (2002), argue that the benefits of employing people with disabilities far outweigh the costs. They found that costs associated with recruiting workers with a disability were lower and the productivity was equal or even greater than hiring non-disabled employees (Graffam et al., 2002).

Thus, people with disabilities can make positive contributions towards social, economic and community development if opportunities and support are provided for them to participate in meaningful employment activities (Funnell, 2009). Considerations might include communities and employers creating opportunities for people with disabilities to be utilised in areas of their expertise (Funnell, 2009). For example, providing opportunities for people with disabilities to use their practical or professional skills and knowledge, as well as ensuring that they are more actively involved in community work (Funnell, 2009). Most importantly, the Australian government's social inclusion agenda focuses on addressing the different challenges experienced by people with disabilities in the employment sector to help ensure their full participation in paid and volunteering employment (Waterhouse et al., 2010; NPDCC, 2009).

Consequently, some people with disabilities participate in the workforce and make valuable contributions towards economic development and social capital (ABS, 2009; Bruce, 2006). The ABS (2009) statistics show that a significant number of working-age people with disabilities who participated in the workforce in 2009 engaged in different occupations, including professional, clerical and administrative, technical and trade positions. In terms of employment, both disabled and non-disabled people had similar employment distributions across different occupations and industry groups (ABS, 2009). Additionally, the workforce participation for people with disabilities incorporates contributions that might provide economic and social benefits, as well as reducing the practical costs associated with social exclusion (Metts, 2000).

\section{Types of disability}

The ABS (2009) survey of disability, ageing and carers has classified disability into different groups, including physical, sensory or speech, intellectual, head injury, stroke or brain damage and psychological disability. The ABS (2009) statistics on disability employment indicated that the most common in 2009 was physical disability, which had affected a large proportion equivalent to 71 percent of working-age individuals with a disability. The sensory and speech disability was calculated at 21 percent, whereas psychological impairment affected about 17 percent of the target population (ABS, 2009). Furthermore, the type of impairment that an individual exhibits can affect their employment prospects (ABS, 2009). People with speech or sensory impairment had achieved better employment outcomes with a participation rate of 54 percent, and an unemployment rate of 7 percent (ABS, 2009). Subsequently, people with psychological impairment had the lowest participation rate equivalent to 29 percent, with the highest unemployment rate at 19 percent (ABS, 2009). Research indicates that people with speech or sensory impairment might benefit from assistive equipment, but may not be useful for individuals with psychological disability, including mental illness (Waghorn \& Lloyd, 2005). Consequently, people with mental illness may also experience employment challenges in terms of maintaining punctuality or work 
attendance standards, and even interruption in their profession due to the sporadic occurrences of their disability (Waghorn \& Lloyd, 2005).

\section{Inclusive interventions and strategies}

To address the second part of the research question, two different community development projects were selected and reviewed. These two projects were predominantly chosen as they specifically focused on employment challenges for people with disabilities in Australia; and outlined strategies and solutions that promoted client ownership of the research process. Research indicates that effective practice takes an inclusive approach and allows clients to take ownership of solutions in relation to addressing the challenges they experience in the employment sector (Bruce, 2006; Volunteering Tasmania, 2010). Additionally, both projects incorporated research methodologies that focused on inclusive interventions that helped improve employment outcomes for people with disabilities. Most importantly, the projects met the inclusion criteria focusing on adult participants with disabilities. No other research met these criteria. Both projects were aimed at supporting people with disabilities in gaining a voice and advocating for inclusive practice in the employment sector through action research. Each project will be discussed in turn.

\section{Study one}

The first project was conducted in Victoria by a community development professional with the aim to support consumers to convey a message to volunteer and community organisations, as well as expressing the views and opinions of disabled people regarding disability employment concerns. Following several consultations, involvement and mutual collaboration with different people with disabilities from the local community, the researcher identified and outlined the obstacles which disabled people experienced in seeking employment opportunities and in performing such roles. After listening to concerns raised by people with disabilities, the community development professional engaged with a group of twelve people with disabilities from the community to investigate volunteering and community options for them. Members of this project group consisted of participants with a disability between 18 and 22 years of age from across the community. Through mutual cooperation, the community development worker together with members of the project group engaged in the process of sharing ideas and feelings on the subject of volunteering and participation in community work (Bruce, 2006).

In this process, the community development worker discovered that the target population was very eager to volunteer and be involved in employment activities. Additionally, consumers were looking for meaningful ways in which they could become involved in community and employment activities. Members of the project group stated there was a need for community organisations and potential employers to become better informed about disabled people and their abilities, to become aware of access issues for them, and to create meaningful opportunities that people with disabilities can participate in, and as such achieve a goal of helping and contributing to the wider society (Bruce, 2006).

During this process, it became quite obvious that finding out about the role of volunteer and community organisations was one of the biggest barriers facing people with disabilities. To overcome this obstacle the researcher together with members of the project group decided to hold a Volunteering and Community Options Expo to bring about understanding and finding out about volunteer organisations and opportunities that could be available for them (Bruce, 2006). The Volunteering and Community Options Expo was a great success, providing two-way learning for disabled people, volunteering and community organisations (Bruce, 2006). This activity provided a platform for involving and strengthening communities of people with disabilities. 
This exhibition was an opportunity to demonstrate what community organisations are doing and for people to ask questions, get answers and become active. During this event, surveys were sent out to community organisations and they returned feedback stating that some organisations were not sure how to support or engage an individual with a disability (Bruce, 2006). This exhibition was an opportunity to address this barrier, raising awareness and bringing an understanding about disabled people and their abilities. The outcome of this project was positive because volunteering and community organisations enhanced their understanding of disability employment issues. By doing so, the voice of people with a disability was heard, as they were offered an opportunity to be valued for the contribution they can make to their communities.

\section{Study two}

The second project was conducted by a local community organisation in Tasmania (Volunteering Tasmania, 2010). The project was aimed at advocating volunteering and to find out about issues relating to the involvement of people with disabilities as volunteers, to identify common obstacles to their involvement in volunteering, to find solutions and suggestions for overcoming those barriers, as well as maximising the involvement of people with disabilities in volunteering. Through consultation with people with disabilities and community organisations, strategies to collect information were developed, including surveys, a workshop and case studies with a series of interviews to learn more about different views on disability employment issues. The aforementioned strategies were adopted as they provided flexibility, a list of questions and opportunities for discussion with the ability to gain qualitative data to support the research recommendations (Volunteering Tasmania, 2010).

The project achieved positive outcomes because barriers to involving people with disabilities in volunteering work were identified and dealt with. Responses from surveys, workshop and interviews incorporated positive answers from some community organisations, which did not have volunteers with a disability, stating that they are willing to involve a person with a disability as long as the potential volunteer could meet the essential requirements of the volunteer position. Others indicated that there was a need to identify the abilities of a potential volunteer, their experience, skills and training in order to match them to an appropriate role (Volunteering Tasmania, 2010). This would allow for recruiting volunteers with disability specifically for their practical or professional skills.

Results also indicated that there was a need to treat volunteers who have a disability with respect, to uphold their independence and treat them in a fair and reasonable manner, as well as ensuring that management practices, such as the recruitment process, are nondiscriminatory (Volunteering Tasmania, 2010). People's attitudes and perceptions about involving individuals with a disability were enlightened. The project suggested and emphasised the need for community and volunteering organisations to look at an individual's abilities rather than just focusing on their disability (Volunteering Tasmania, 2010).

\section{Summary of both studies}

Methods and strategies in both projects incorporated community development, community action and community capacity building perspectives (Ife, 1995). For example, in the first project the 0-1-3 community development method, which "builds relationships amongst people and creates groups by which public action can take place" (Ingamells et al., 2010, p. 21), was adopted. This is evident as the community development worker consulted with clients to share in the action research topic regarding the involvement of individuals with disabilities in community work. Agreement was reached and the idea was moved from being a private to a public concern or interest (Burkett, 2007; Ingamells et al., 2010). 
The activities conducted in both projects, such as holding an exhibition and a workshop and sending out surveys, where mechanisms to advocate for inclusive practice and to empower people with disabilities by assisting them to get their voices heard by community organisations. Generally, these projects have met the criteria established to measure the expected outcomes of this research task, which focussed on comparing the work done in these projects with principles, strategies and methods of action research.

\section{Links between volunteering and paid employment}

Literature findings from a range of sources, including researchers, the Australian government, peak volunteering bodies and disability service providers have all concluded that there is a strong link between volunteer work and paid employment (Australian Government, 2009; Held \& Granholm, 2007; Institute for Volunteering Research, 2009; Mencap, 2009a; Reilly, 2005). Volunteering encompasses a range of benefits that can improve employment outcomes for people with disabilities seeking paid employment, including but not limited to acquiring new skills, increased self-worth and confidence (Held \& Granholm, 2007). Mencap (2009b) concluded that work experience gained through volunteering is a significant outcome for people with disabilities looking for paid employment. Reilly (2005) states that some research participants with disabilities reported that volunteering had improved their employment outcomes.

Volunteering is an integral mechanism towards improving employment outcomes for people with disabilities, as well as enhancing their participation in community activities (Bruce, 2006; Reilly, 2005; Volunteering Tasmania, 2010) and expanding their social networks (Balandin, Llewellyn, Dew, Ballin, \& Schneider, 2006; Choma \& Ochocka, 2005). As a result, work experience for people with disabilities is one key strategy to address some of the challenges they experience when seeking to enter the paid workforce (Waterhouse et al., 2010). Literature shows that potential employers have confidence in a job-seeker with a disability if that person has a record of previous volunteer or some work experience (Waterhouse et al., 2010). Employers might then consider the previous volunteer provider as a reliable and trusted broker or source of information in relation to recruiting an applicant with a disability (Waterhouse et al., 2010). In most cases, volunteering for people with disabilities, and even for non-disabled people, is a useful life experience that can lead towards securing paid employment (Held \& Granholm, 2007; Reilly, 2005). In this case, volunteering or work experience is perceived as an employment pathway for job-seekers with disabilities (Held \& Granholm, 2007; Mencap, 2009a). Access to volunteering or work experience is predominantly beneficial and an essential component of the job-seeking process for people with disabilities seeking to enter the paid workforce (Waterhouse et al., 2010).

\section{Employment support for people with disabilities in Australia}

There is a number of specialist employment support services funded by the Australian government which help people with disabilities obtain and maintain work, including Disability Employment Services (DES) and Australian Disability Enterprises (ADE) (Department of Human Services [DHS], 2016; Women With Disabilities Australia [WWDA], 2016). The DES provide employment support to people with disabilities seeking to enter the workforce through a network of organisations across Australia; whilst the ADE are commercial enterprises which employ and provide ongoing and intensive support to people with disabilities to achieve employment outcomes (DHS, 2016; WWADA, 2016).

Furthermore, the social enterprise model that embraces and upholds core principles of social inclusion provides fundamental employment frameworks to increase the employability of people with disabilities. Social enterprises are businesses that are set up for the principal 
purpose of delivering social outcomes through trading activities (Mestan \& Scutella, 2007). Profit-making social enterprises use the majority of their profits to advance social goals (Mestan \& Custella, 2007). Social enterprises' goals are particularly significant in contributing to local economic development by increasing employment opportunities of people with disabilities and those who are disadvantaged or being excluded in the labour market (Finn \& Simmonds, 2003; Mestan \& Custella, 2007). The social enterprise model also provides vital strategies and responds positively to the needs of people who are at risk of long term unemployment (Mestan \& Scutella, 2007).

Social firms are businesses that focus on enhancing the employability of people with disabilities and to provide them with support related to maximising their employment opportunities in the open labour market (Warner \& Mandiberg, 2006). Whilst there is a range of social needs that the social enterprise model is responding to, in Australia and overseas there is a growing need for social enterprises that respond to the real needs of those people unable to obtain employment (Finn\& Simmonds, 2003; Mestan \& Scutella, 2007). The social enterprise theory, such as the integrated perspective which combines together factors, such as work experience placements, time-limited traineeships and ongoing supported employment within a trading business context (Jensen, 2006; Mummery, 2007), might help achieve this important objective.

\section{The National Disability Insurance Scheme (NDIS)}

The NDIS is one of the Australian federal government's key strategies toward achieving social inclusion for people with disabilities (NDIS, 2016). The NDIS aims to provide support to people with a permanent and significant disability which impacts on their ability to be involved in their day to day life activities (NDIS, 2016). Supports will help participants achieve their desired goals in different areas of life, including providing independence, participation in community, education, employment, health and wellbeing activities (NDIS, 2016). The NDIS seeks to give participants more choice and control over how, the time and place their disability supports should be provided (NDIS, 2016). If necessary, the NDIS shall also be inclusive of families and carers in relation to developing support plans for participants (NDIS, 2016). Additionally, the NDIS provides funding to relevant supports to help participants achieve their goals, such as therapeutic interventions, home modifications, mobility equipment, as well as participation in community and employment activities (NDIS, 2016).

\section{The United Nations Convention on the Rights of Persons with Disabilities (UNCRPD)}

The UNCRPD (2006) sets out principles that are focused on enhancing opportunities for people with disabilities to take part in all aspects of life, such as access to employment, education, health care, to name a few. The convention supports the right of people with disabilities to work, as equally as non-disabled people, including obtaining sustainable employment in the open labour market (UNCRPD, 2006). The convention's article on work and employment promotes social rights' principles, such as prohibiting employment discrimination on the basis of disability, promoting employment opportunities and career development, self-employment, work place adjustments for people with disabilities, and many more (UNCRPD, 2006). Generally, the convention aims to promote, defend and reinforce the human rights of all people with disabilities (UNCRPD, 2006).

\section{Implications for practice}

Employment disadvantage related to social exclusion is a key concern, not only for consumers but also for organisations and helping professionals who work in the disability employment sector as it can negatively impact on organisational and service delivery outcomes (CRS Australia, 2012). Hence, the research question articulated in this paper has 
important implications for practice, both for the rehabilitation counselling profession and the disability employment services sector in Australia. The principal author of this paper developed an interest in this topic based on his previous studies in rehabilitation counselling and previous work experience within a large disability employment organisation in Australia. The author observed practice in this organisation and found that job seekers with disabilities experienced various challenges in obtaining sustainable employment in the open labour market due to issues related to community and employer misconceptions and lack of awareness about disability issues.

Based on the literature review and the findings of the two community development projects, it is evident that people with disabilities experience significant challenges in the employment sector in Australia. The following recommendations are made with the view to reducing barriers and increasing the participation of people with disabilities in the workforce, including volunteering and paid employment in Australia. Literature suggests that the following activities be carefully considered and put into practice to improve employment outcomes for people with disabilities in Australia:

Firstly, community organisations and potential employers should adopt a proactive and planned approach in the employment of people with disabilities (NCVER, 2010). It is suggested that clearly defined policies be published to deal with the disability employment issues. Volunteering Tasmania (2010) concluded that for these policies to have any meaning they should contain information relating to the following:

- The employment procedures for dealing with job seekers with a disability

- A reference list to facilities and aids or support systems already in place within the organisation for accommodating people with disabilities

- A reference list of external consultants and relevant agencies that assist in the recruitment and placement of people with disabilities

- Summaries and implications of specific aspects of legislation which deal with the employment of people with disabilities.

Secondly, it is recommended that community organisations and potential employers conduct in-depth investigations of both the physical and social aspects of workplaces to identify the actual barriers to employing people with a disability. In terms of investigating the physical environment, organisations can either choose to conduct investigations internally or make use of external consultants through workplace assessments (CRS Australia, 2012). An investigation of barriers, which are of a social nature, would predominantly involve people with disabilities already working within the organisation. In this regard, it is recommended that questionnaires be sent to, or interviews be conducted with people with disabilities to determine the difficulties or challenges they experienced in working with able-bodied individuals. This would enable organisations and potential employers to develop proactive intervention plans, including but not limited to the provision of more comfortable facilities and work equipment, job re-designing and other strategies to improve the employment outcomes of people with disabilities. There is also the need to establish a body that will provide expert advice to employers on how to make workplaces accessible and disability-friendly.

Thirdly, there is a need for national awareness campaigns to mobilise employers to recruit people with disabilities, as well as encouraging disabled people to disclose their disability to potential employers for the right support to be provided to them. Finally, considering the competitive nature of the labour market, people with disabilities should endeavour to acquire 
adequate skills and educational qualifications. This would help improve their employment outcomes, as well as increasing employment opportunities regardless of their disabilities.

\section{Implications for research}

The research described in this literature review focused on exploring the challenges experienced by people with disabilities in the employment participation, and the interventions that are effective from the perspectives of people with disabilities. Consequently, employers' perspectives and concerns about support requirements to help increase the employability of people with disabilities have received little attention (Domzal et al., 2008; Waterhouse et al., 2010). This means, the current literature has largely focused on support needs of people with disabilities and the essential requirements in relation to obtaining employment. On the other side, there are knowledge gaps regarding employers' perspectives or concerns about disability employment, as well as, their expectations when employing people with disabilities (Waterhouse et al., 2010). Employers' voices and support needs or requirements have not been broadly investigated (Waterhouse et al., 2010). Further research might investigate employers' perspectives in relation to facilitating employment opportunities for people with disabilities. Additional research could also focus on exploring the support systems and other complementary policy measures that could support employers to consider and engage disabled people as able participants in the workforce.

\section{Conclusion}

This literature review found that improving physical access, social working environments, education and disability awareness, training and support requirements are integral part of the inclusive practice, as well as achieving successful employment outcomes for people with disabilities (NPDCC, 2009). The inclusive approach is a fundamental mechanism and proactive strategy to help address the challenges and barriers to meaningful employment for people with disabilities. Community organisations and potential disability employment agencies are called to lead the way to include people with disabilities in community activities and mainstream employment opportunities. This would help reduce misconceptions of disability issues and promote the principles of social inclusion. Community and employers' concerns leading to the exclusion of people with disabilities from accessing mainstream employment opportunities have also been discussed. This literature review has found that benefits associated with employing people with disabilities far exceed the disadvantages. The link between volunteering and paid employment, as well as the benefits associated with volunteering for people with disabilities seeking to enter the workforce have been explored. The paper has provided a brief description of the social enterprise model and discussed how social enterprise techniques could be used to increase the employability of people with disabilities. Employment supports and key strategies towards achieving social inclusion, as well as human rights' principles on work and employment for people with disabilities have been highlighted. Most importantly, the Disability Discrimination Act (1992) stipulates that "any adjustments or alterations, which would enable the person with a disability to carry out the inherent requirements of a job, must be made unless this imposes unjustifiable hardship on the employer". Thus, promoting relevant legislation, disability employment policies and social rights' principles is an integral part of mechanisms to addressing the barriers to employment for people with disabilities. 


\section{References}

Australian Bureau of Statistics. (2003). Disability, Ageing and Carers, Australia: Summary of Findings, 2003. (Catalogue No. 4430.0). Retrieved from http://www.abs.gov.au/AUSSTATS/abs@.nsf/DetailsPage/4430.02003?OpenDocu ment

Australian Bureau of Statistics. (2009). Disability, ageing and carers, Australia: Summary of findings, 2009. (Catalogue No. 4430.0). Retrieved from http://www.abs.gov.au/AUSSTATS/abs@.nsf/Lookup/4430.0Main+Features12009?O penDocument

Australian Bureau of Statistics. (2012). Australian social trends, March Quarter 2012. (Catalogue No. 4102.0). Retrieved from http://www.abs.gov.au/AUSSTATS/abs@.nsf/Lookup/4102.0Main+Features40March +Quarter+2012

Australian Employers Network on Disability. (2008). Managers' guide: Disability in the workplace. Retrieved from http://www.and.org.au/pages/managers-guide-disability-inthe-workplace.html

Australian Government. (2009). Work experience: Voluntary work. Canberra, Australia: Job Services Australia.

Australian Industry Group. (2005). Al group submission: National inquiry into disability and employment.. Retrieved from http://www.aigroup.asn.au/aigroup/pdf/representation/submissions/hreoc-disabilityapril05.pdf

Balandin, S., Llewellyn, G., Dew, A., Ballin, L., \& Schneider, J. (2006). Older disabled workers' perceptions of volunteering. Disability \& Society, 21(7), 677-692. doi:10.1080/09687590600995139

Boyce, W., Malakar, S. Millman, R., \& Bhattarai, K. (1999). Physically disabled children in Nepal: a follow up study. Asia Pacific Disability Rehabilitation Journal, 10(1), 20-26.

Bruce, L. (2006). Count me in: people with a disability keen to volunteer. Australian Journal of Volunteering, 11(1), 59-64.

Buckup, S. (2009). The price of exclusion: The economic consequences of excluding people with disabilities from the world of work. International Labour Organisation. Retrieved from http://www.ilo.org/employment/Whatwedo/Publications/workingpapers/WCMS_119305/lang--en/index.htm

Burkett, I. (2007). Note from Editor. In A. Lathouras (author). The Srikandhi and united in diversity groups: A story of community development from Nambour, Queensland. International Association for Community Development Newsletter, August, 6-7.

Choma, B.L. \& Ochocka, J. (2005). Supported volunteering: A community approach for people with complex needs. Journal on Developmental Disabilities, 12(1), 1-18. Commonwealth Department of Social Services.. (2011). National Disability Strategy 2010 - 2020. Canberra, Australia. Retrieved from https://www.dss.gov.au/ourresponsibilities/disability-and-carers/publications-articles/policy-research/nationaldisability-strategy-2010-2020

Commonwealth Department of Social Services. (2011). National Disability Strategy 2010 2020. Canberra, Australia. Retrieved from https://www.dss.gov.au/ourresponsibilities/disability-and-carers/publications-articles/policy-research/nationaldisability-strategy-2010-2020

Craddock, G. \& McCormack, L. (2002). Delivering an AT service: a client- focused, social and participatory service delivery model in assistive technology in Ireland. Disability \& Rehabilitation, 24(1-3), 160-170. 
CRS Australia. (2012). Effective disclosure strategy: Gaining job seeker consent to work with employers - background information. Canberra, Australia.

Department of Education, Employment and Workplace Relations. (2011). Evaluation of Disability Employment Services Interim Report, June.Canberra, Australia. Retrieved from

http://www.deewr.gov.au/Employment/ResearchStatistics/ProEval/Documents/DES2 011interimeval.pdf

Department of Human Services. (2016). Disability Employment Services. Canberra, Australia. Retrieved from https://www.humanservices.gov.au/customer/services/centrelink/disabilityemployment-services

Disability Discrimination Act 1992. Federal Register of Legislation. Retrieved from https://www.legislation.gov.au/Details/C2015C00252. Pp.13,15 \& 37.

Domzal, C., Houtenville, A. \& Sharma, R. (2008). Survey of employer perspectives on the employment of people with disabilities: Technical report. McLean, VA: Office of Disability and Employment Policy, US Department of Labor..

Finn, D. \& Simmonds, D. (2003). Intermediate labour markets in Britain and an international review of transitional employment programmes. Department for Work and Pensions.

Funnell, B. (2009). Inviting people with disability to be volunteers or (Overlooking the contribution of people with disability is a disservice to us all). Brisbane, Australia: CRU Publications.

Geisen, T. (2011). Workplace disability management as an instrument for human resources and organisational development. In T. Geisen \& H. Harder (Eds.), Disability management and workplace integration: International research findings (pp. 13-26). Surrey, England: Gower Publishing.

Graffam, J., Shinkfield, A., Smith, K., \& Polzin, U. (2002). Employer benefits and costs of employing people with disability. Journal of Vocational Rehabilitation, 17(4), 251263.

Held, M. \& Granholm, P. (2007). Volunteering as a route (back) to employment: Executive summary. Paris, France: European Volunteer Centre.

Human Rights and Equal Opportunity Commission. (2005). WORKability II: Solutions:People with disabilities in the open workplace. Sydney, Australia.

Ife, J.W. (1995). Community development: creating community alternatives-vision, analysis and practice. Melbourne, Australia: Longman Australia.

Ingamells, A., Lathouras, A., Wiseman, R., Westoby, P., \& Caniglia, F. (2010). Community development practice: Stories, method and meaning. Altona, Victoria: Common Ground.

Institute for Volunteering Research. (2009). The benefits of volunteering for employability key findings from recent research by The Institute for Volunteering Research.

Retrieved from http://www.ivr.org.uk/researchbulletins/The+benefits+of+volunteering+for+employa bility+\%E2\%80\%93+key+findings+from+recent+research+by+The+Institute.htm.

Jensen, A. (2006). Insolvency, Employee Rights \& Employee Buyouts: A Strategy for Restructuring. The Common Cause Foundation. Retrieved from http://www.efesonline.org/LIBRARY/2006/Insolvency,\%20Employee\%20Rights $\% 20 \& \% 20$ Employee\%20Buyouts.pdf

Keating, M., Beaton, L., \& Foster, B. (2007). Showcasing equity employers. Collingwood, Vic: Equity Research Centre.

Kulkhanchit, T. (2002). Response to research questionnaire. President, Nonthaburi Society of Disabled Persons, Thailand.

Lewis, G. \& Priday, G. (2008). National disability partnership project: Preliminary 
findings.. Perth, WA:EDGE Employment Solutions Inc.

Mencap (2009a). Finding a Job. Cited in Trembath, D.; Balandin, S.; Stancliffe, R. J.; \& Togher, L. (2010). Employment and Volunteering for Adults With Intellectual Disability. Journal of Policy and Practice in Intellectual Disabilities. Vol 7 (4). Pp 235238. University of Sydney, NSW \& Molde University College, Molde.

Mencap (2009b). Mencap Advance: Preparing for work. Cited in Trembath, D.; Balandin, S.; Stancliffe, R. J.; \& Togher, L. (2010). Employment and Volunteering for Adults With Intellectual Disability. Journal of Policy and Practice in Intellectual Disabilities. Vol 7 (4). Pp 235-238. University of Sydney, NSW \& Molde University College, Molde.

Mestan, K., Scutella, R. \& Allen Consulting Group. (2007). Investing in people: Intermediate labour markets as pathways to employment. Brotherhood of St. Laurence, Fitzroy. Retrieved from http://www.bsl.org.au/pdfs/Investing_in_people_ILMs_summary.pdf

Metts, R. L. (2000). Disability issues, trends and recommendations for the World Bank. World Bank, Washington, D.C. USA.

Moore, D. \& Fishlock, S. (2006). Can do volunteering: A guide to involving young disabled volunteers. Retrieved from https://www.energizeinc.com/art/subj/documents/canDOweb.pdf

Morgan, R.L. \& Alexander, M. (2005). The employer's perception: Employment of individuals with developmental disabilities. Journal of Vocational Rehabilitation, 23(1), 39-49.

Mummery, F. and BCG. (2007). A Guide to starting a recycling venture in your community. Eaglehawk Recovery Centre Yackandandah Petrol Station. Retrieved from http://www.yackandandah.com/ycdco/AboutUs.html

National Disability Insurance Scheme. (2016). What is the National Disability Insurance Scheme? Retrieved from http://www.ndis.gov.au/about-us/what-ndis

National People with Disabilities Carers Council. (2009). Shut out: The experience of people with disabilities and their families in Australia. Canberra, Australia: Commonwealth Government of Australia.

Reilly, C. (2005). Volunteering and disability: Experiences and perceptions of volunteering from disabled people and organisations. Stirling, Scotland: Volunteer Development Scotland.

Royal Australasian College of Physicians [RACP] \& The Australasian Faculty of Occupational and Environmental Medicine. (2011). Position statement on realising the health benefits of work. Retrieved from https://www.racp.edu.au/docs/defaultsource/advocacy-library/realising-the-health-benefits-of-work.pdf?sfvrsn=10

Smith, K., Webber, L., Graffam, J., \& Wilson, C. (2003). Employer satisfaction with employees with a disability: Comparisons with employees. Journal of Vocational Rehabilitation, 21(2), 61-9.

Taleporos, G. (2014). Employment and disability: A complex problem with no simple solution. Ramp Up for $A B C$.. Retrieved from http://www.abc.net.au/rampup/articles/2014/01/13/3922428.htm

Thomas, A., \& Hlahla, M.A. (2002). Factors that influence the employment of people with disabilities in South Africa. South African Journal of Labour Relations, 26(4), 432.

United Nations Convention on the Rights of Persons with Disabilities (2006). Convention on the Rights of Persons with Disabilities. Retrieved from http://www.un.org/disabilities/convention/conventionfull.shtml

Volkoff, V., Clarke, K., \& Walstab, A. (2008). Impact of TAFE inclusiveness strategies. Adelaide, South Australia: The National Centre for Vocational Education Research. Retrieved from https://www.ncver.edu.au/publications/publications/allpublications/impact-of-tafe-inclusiveness-strategies 
Volunteering Tasmania (2010). Inclusive practice volunteering. Retrieved from http://www.volunteeringtas.org.au

Waghorn, G. \& Lloyd, C. (2005). The employment of people with mental illness: Discussion paper for the Mental Illness Fellowship of Australia. Marleston, South Australia: Mental Illness Fellowship of Australia.

Warner, R. \& Mandiberg, J. (2006). An update on affirmative businesses or social firms for people with mental illness. Psychiatric Services, 57(10), 1488-1492.

Waterhouse, P., Kimberley, H., Jonas, P., \& Glover, J. (2010). What would it take? Employer perspectives on employing people with a disability. Adelaide, South Australia: National Centre for Vocational Education Research.

Winefield, A.H., Montgomery, B., Gault, U., Muller, J., O'Gorman, J., Reser, J., \& Roland, D. (2002). The psychology of work and unemployment in Australia today: An Australian psychological society discussion paper. Australian Psychologist, 3(1),1-9.

Women With Disabilities Australia (2016). Employment programs for people with disabilities. Retrieved from http://wwda.org.au/govtdis/govtdisprogram/employprog1/ Yeend, P. (2012). Budget 2011 - 12: Disability support pension-reforms. Canberra, Australia: Parliament of Australia. Retrieved from http://www.aph.gov.au/about_parliament/parliamentary_departments/parliamentary_li brary/pubs/rp/budgetreview201112/disability 


\section{Biographical Notes}

Amos Ruhindwa has completed a Bachelor of Human Services - Rehabilitation Counselling major in 2012, and a Master of Human Services in 2013 at Griffith University. He received the Griffith Award for Academic Excellence 2013 upon completion of his Master's degree with a grade of Distinction. His research interests include community development, social inclusion and human rights for disadvantaged groups. His previous practice experience involves case management and rehabilitation counselling work within the human services field, and currently in a mental health support coordinator role in a local community organisation. He looks forward to undertaking further studies and advancing his knowledge in social inclusion, human rights and community development practice.

Dr Christine Randall is a Lecturer in Rehabilitation Counselling in the School of Human Services and Social Work, where she teaches injury management, vocational decision making and case management courses. Christine convenes rehabilitation counselling and industry programs for the personal injury industry, as well as convening field placement for postgraduate students in rehabilitation counselling and human services.

Her research interests include occupational rehabilitation systems in organisations and workplace stress, rehabilitation counselling competencies, disability management, and case management. Christine's doctoral research utilised Action Research to identify the issues related to occupational stress and rehabilitation systems within a large Australian organisation to develop more effective integrated systems of stress and injury prevention and rehabilitation. Christine is a member of the International Disability Management Researchers Network and GLADNET, as well as a founding director of the Rehabilitation Counselling Association of Australasia (RCAA).

Dr Jennifer Cartmel is a Senior Lecturer School of Human Services and Social Work has experience teaching, researching and in practice with children and families particularly in services including school age care, schools, and integrated children's services. Her key areas of interest are workforce development, critical reflection and well-being. 